\title{
AS REPRESENTAÇÕES DOCENTES SOBRE AS CAUSAS DA INDISCIPLINA NA ESCOLA: DE QUEM É A CULPA?
}

Elisabeth Ramos da SILVA ${ }^{1}$

Maria José Milharezi ABUD ${ }^{2}$

\begin{abstract}
Resumo: Este trabalho apresenta uma pesquisa realizada com 20 professores de língua portuguesa do ensino fundamental e médio que se queixavam da indisciplina em sua escola. $\mathrm{O}$ objetivo foi investigar quais as representações docentes acerca dos fatores aos quais eles atribuem o comportamento inadequado dos alunos. Para tanto, foi solicitado a esses professores que respondessem à seguinte questão: para melhorar a disciplina na escola, o que poderia ser feito? Certamente os fatores apontados por esses docentes indicam a quê ou a quem eles atribuem a culpa pelo comportamento inadequado dos alunos. As respostas foram analisadas segundo os constructos da Análise de conteúdo proposta por Bardin (2010). Os resultados revelaram que o professor responsabiliza principalmente a atuação docente como a maior causa dos atuais problemas de indisciplina na escola, isto é, nas representações desses docentes a culpa recai principalmente sobre sua própria atuação na sala de aula, o que acentua a sua desvalorização e a perda da autoridade junto aos alunos.
\end{abstract}

Palavras-chave: Formação de professores. Causas da indisciplina. Autoridade docente.

\section{Introdução}

A disciplina é considerada um fator indispensável quando se trata das relações presentes em qualquer instituição, seja ela escolar, militar, religiosa, entre outras. No entanto, o próprio termo disciplina admite várias concepções. De fato, no dicionário, onde se encontra, em geral, a forma denotativa de explicitar um termo, há várias possibilidades de entender esse verbete. Disciplina, segundo Ferreira (2009), pode ser "Regime de ordem imposta ou livremente consentida. Ordem que convém ao funcionamento regular duma organização (militar, escolar,

\footnotetext{
${ }^{1}$ Professora e pesquisadora do Programa de Mestrado em Linguística Aplicada da Universidade de Taubaté. Email: lis.ramos@uol.com.br

${ }^{2}$ Professora e pesquisadora do Programa de Mestrado em Linguística Aplicada da Universidade de Taubaté. Email: m.jose.abud@uol.com.br
} 
etc.). Relações de subordinação do aluno ao mestre ou ao instrutor. Observância de preceitos ou normas. Submissão".

Como se pode notar, a disciplina pode ser entendida de forma pejorativa e cerceadora (ordem imposta, submissão), ou de forma construtiva e otimista (livremente consentida, observância de preceitos e normas). Isto significa que a maneira como o indivíduo conceber esse termo será um fator determinante para orientar, no caso do professor, suas ações docentes e, no caso do aluno, sua conduta na instituição de ensino. Daí podermos encontrar abrigadas no mesmo termo atitudes notadamente autoritárias ou iniciativas de natureza democrática e consensual que visem a garantir a disciplina em sala de aula.

Em contrapartida, a indisciplina é entendida sempre como uma condição nociva ao êxito de qualquer trabalho, sobretudo quando se trata das interações que ocorrem no ambiente escolar. De fato, no dicionário, vemos que indisciplina é definida como "Procedimento, ato ou dito contrário à disciplina; desobediência; desordem; rebelião" (FERREIRA, 2009). Daí podermos concluir que, quando se trata do ambiente escolar, cabe aos profissionais de ensino garantir a disciplina sob pena de permitir a desordem e a rebelião às normas. Em outros termos, pode-se dizer que permitir atos indisciplinares aos alunos constitui uma grave lacuna no sistema de ensino de uma escola; portanto, a indisciplina precisa ser combatida de forma diligente e contínua. Aquino (1996, p. 40) afirma que "a indisciplina seria, talvez, o inimigo número um do educador atual [...]". De fato, ela se configura como "um obstáculo pedagógico", "um novo problema que pede passagem" (AQUINO, 1996, p. 41).

Cremos que a forma como o docente entende as causas da indisciplina e a forma de combatê-la indicam não apenas os fatores que a deflagram, mas também como os docentes identificam os responsáveis por existir tal lacuna na escola. Por isso, em nossa pesquisa, perguntamos ao professor: "Para melhorar a disciplina na escola, o que poderia ser feito?". Trata-se de verificar, de forma indireta, a quem o professor atribui os problemas de indisciplina que a escola enfrenta, ou seja, a quem ou a quê ele atribui a culpa do comportamento inadequado de seus alunos. De fato, ao dar sugestões sobre o que poderia ser feito para melhorar a disciplina, o professor terá que apontar os fatores que agora considera como responsáveis por haver indisciplina. Se ele, por exemplo, sugerir mais participação da família, estará responsabilizando a ausência dos pais como um fator que desencadeia a indisciplina. Se apontar as estratégias utilizadas pelo professor, ele estará considerando o docente como um dos responsáveis pelas atitudes indisciplinadas nos alunos, e assim por diante.

Como fundamentação teórica, abordaremos neste trabalho os esclarecimentos de estudiosos acerca da indisciplina na escola, bem como exporemos algumas reflexões acerca do 
papel do professor, sobretudo no que concerne à sua autoridade em sala de aula, e do papel da família que, segundo La Taille (2010), seria a instituição social responsável pela educação primária do sujeito. Em seguida, exporemos os procedimentos metodológicos, os dados e as análises da pesquisa. Cremos que os resultados deste estudo podem contribuir para que o fenômeno da indisciplina possa ser mais bem compreendido pelos profissionais que atuam nas escolas.

Este trabalho se insere no âmbito da Linguística Aplicada por considerar a linguagem como fonte de nossas indagações e respostas, revelando as representações docentes acerca do fenômeno da indisciplina nas escolas. Daí optarmos como procedimento metodológico pelos constructos da Análise de conteúdo proposta por Bardin (2010), que nos permite ir além do significado aparente dos enunciados, possibilitando-nos formular categorias de análise e identificar a frequência com que estas ocorrem.

\section{Indisciplina na escola: o que é?}

Não é raro ouvirmos professores apontarem culpados pelos problemas da indisciplina escolar, muitas vezes restringindo suas análises apenas às circunstâncias da sala de aula passíveis de serem observadas por eles. Outras vezes, eximem da escola qualquer responsabilidade, impondo à família o ônus da má conduta do aluno. No entanto, não convém interpretar a indisciplina na escola sem levar em conta os fatores socioculturais e psicológicos envolvidos nas diversas situações de ensino, tais como a linguagem, os valores, as pressuposições, entre outras. É preciso considerar que as explicações referentes ao fenômeno indisciplina envolvem diferentes dimensões. Por isso, La Taille (1996, p. 9-10) nos adverte sobre o risco do reducionismo, que explica um fato por apenas uma dimensão. $\mathrm{O}$ autor alega que, se disciplina for entendida como "comportamentos regidos por um conjunto de normas", então indisciplina poderá ser ou a revolta contra essas normas, ou o desconhecimento delas (p. 10). No primeiro caso, consistirá em "desobediência insolente", e, no segundo, em comportamentos caóticos e desorganização das relações (LA TAILLE, 1996, p. 10). O autor observa ainda que, hoje, a desorganização das relações provocada pelo desconhecimento das normas parece ser o que estaria fomentando a indisciplina.

Presumimos que a forma como o professor lida com a indisciplina guarda relação com o modo como ele a entende. Em geral, a indisciplina escolar diz respeito à desobediência de certas regras de convivência e de organização. Segundo Amado (2001, p. 417), "A indisciplina implica, sempre, a contravenção de princípios, regulamentos, contratos e ordens, em clara 
discordância com os objetivos do grupo ou instituição e provocando situações de perturbação das relações sociais no seu interior". Nesse sentido, qual seria o papel do professor para evitar tais situações, e qual deveria ser a atuação dos dirigentes escolares?

Se a indisciplina implica a discordância com princípios do grupo, há sem dúvida uma dimensão moral no ato de contravenção a esses princípios. Nesse sentido, La Taille (1996, p. 19-20) acredita que certos atos de indisciplina não podem ser considerados imorais, mas "genuinamente morais", tais como quando o aluno não aceita decisões docentes que lhe pareçam autoritárias ou injustas. Daí o professor estar atento à "razão de ser das normas impostas e dos comportamentos esperados [...]" (p. 20). De fato, as normas devem apresentar razões plausíveis a fim de serem aceitas pelos alunos. Segundo Araújo (1996), é imprescindível que o princípio que sustenta determinada regra seja o da justiça, para que ela não se torne imoral aos olhos dos alunos, fomentando revoltas que, ao contrário de serem atos de indisciplina, configuram-se antes como sendo indícios de autonomia.

Nessa direção, Silva e Neves (2006) acreditam que a indisciplina não é vista da mesma forma pelos professores. Como exemplo, citam o uso de boné em sala de aula, que alguns professores julgam uma contravenção, enquanto outros não. Consideram que os diferentes entendimentos decorrem "possivelmente de, em alguns casos, a indisciplina se reportar aos comportamentos e em outros às significações" (p. 7). Sugerem que talvez por isso a indisciplina seja conceituada de forma tão variada na literatura. Rego (1996) também acredita que a indisciplina é compreendida de várias maneiras, sobretudo devido à diversidade de interpretações que esse assunto suscita e à complexidade que apresenta.

Aquino (1996) aventa que o fenômeno da indisciplina pode indicar a "rejeição operada por esta escola incapaz de administrar as novas formas de existência social concreta, personificadas nas transformações do perfil de sua clientela" (p. 45). Trata-se, portanto, de haver mudanças radicais na instituição escolar a fim de ser capaz de corresponder a esse "novo aluno". A "indisciplina seria sintoma de injunção da escola idealizada e gerida para um determinado tipo de sujeito e sendo ocupada por outro" (AQUINO, 1996, p. 45). Vista por esse prisma, a indisciplina pode tornar-se "força legítima de resistência e produção de novos significados e funções, ainda insuspeitos, à instituição escolar" (AQUINO, 1996, p. 45).

Em contrapartida, La Taille (1996, p. 10) acredita que: "Hoje, o cinismo (negação de todo valor e, logo, de qualquer regra) explica melhor os desarranjos das salas de aula". Não se trata, portanto, de fomentar mudanças na escola, mas de observar a crise de valores que incide na conduta e nas relações humanas. A escola, por ser um espaço onde indivíduos forçosamente devem diuturnamente se relacionar, evidencia claramente esse descompasso com valores 
fundamentais ao convívio humano. Isso, por sua vez, indica que o professor deve empenhar-se na formação de valores, a fim de dirimir conflitos.

Nessa mesma direção, Rego (1996, p. 87) também relaciona a indisciplina com a falta de limites e de respeito ao outro. $\mathrm{O}$ aluno indisciplinado seria aquele que não consegue conviver de modo harmônico com seus pares, uma vez que a disciplina implica a convivência que se traduz, segundo Costa e Barandela (2012, p. 140), como "a capacidade de viver juntos, respeitando-se e estando conforme as normas básicas, resolvendo os conflitos de forma pacífica e prevenindo a sua escalada".

Segundo Rego (1996, p. 96), “um comportamento [...] indisciplinado de um determinado indivíduo dependerá de suas experiências, de sua história educativa, que, por sua vez, sempre terá relações com as características do grupo social e da época histórica em que se insere". Assim, segundo a autora, a indisciplina não deve ser entendida como comportamentos inerentes à 'natureza' de cada aluno ou à faixa etária em que ele se encontra, pois "ninguém nasce rebelde ou indisciplinado" (REGO, 1996, p. 96). Fundamentando-se nos postulados de Vygotsky, a autora analisa a indisciplina como um fenômeno decorrente de vários fatores socioculturais que agem no desenvolvimento do indivíduo. O homem é um ser que se desenvolve e aprende a conviver com o próximo mediante a intervenção de seu grupo cultural. Assim, o comportamento, os valores, as funções psíquicas, entre outros aspectos da vida humana estão intimamente vinculados ao aprendizado. E a escola, por ser a instituição criada especificamente para esse fim, não pode eximir-se da responsabilidade de cultivar o respeito às regras e à convivência com os demais. Segundo a autora, a educação tem um papel muito importante "sobre o comportamento e o desenvolvimento de funções psicológicas complexas, como agir de modo consciente, deliberado, de autogovernar-se (aspectos diretamente relacionados à disciplina)" (REGO, 1996, p. 96). Por isso, cabe à escola e à família, principais agências educativas nessa sociedade, a tarefa de educar a criança e o jovem no que diz respeito à disciplina.

Trevisol e Lopes (2008, p. 24), referenciadas em La Taille (1996), Aquino (1996), Rego (1996) e Araújo (1996), acreditam que a perda de autoridade do professor no que se refere à atitude em sala de aula e ao domínio do conhecimento pode ser uma possível causa da atual indisciplina nas escolas. Assim considerando, convém esclarecer no que consiste essa perda de autoridade do professor e por que tal perda pode ser um dos fatores cruciais que o impedem de debelar as atitudes indisciplinares na escola. 


\section{O professor deixou de exercer autoridade?}

$\mathrm{Na}$ escola, quase sempre as atitudes indisciplinares atribuídas aos alunos dizem respeito ao que ocorre em sala de aula na relação pedagógica dinamizada pelos professores. Cada docente interpreta quais seriam os atos indisciplinares nesse contexto, levando em conta também as normas propostas pela instituição onde trabalha.

Atos indisciplinares são usualmente entendidos como os que incomodam ou atrapalham as relações interpessoais inerentes ao processo de ensino e de aprendizagem, implicando decisões e ações que devem ser adotadas para diminuir os problemas causados por eles. Tais ações, no entanto, não devem ser autoritárias, mas orientadas por princípios democráticos. Em outros termos, enfrentar tais problemas na atualidade requer dos professores "uma nova postura, democrática e dialógica, que entenda os alunos e as alunas não mais como sujeitos passivos ou adversários que devem ser vencidos e dominados" (ARAÚJO, 2007, p. 19).

As inúmeras queixas de educadores a respeito da indisciplina apontam o quanto tem sido difícil trabalhar com os incidentes resultantes de comportamentos inadequados dos alunos entre si e de afrontas indevidas ao professor. O impacto desses incidentes sobre o professor e sobre o processo de aprendizagem tem sido objeto de estudos e de discussões nos meios acadêmicos. E, sem cair no reducionismo, uma vez que a indisciplina envolve vários fatores, o papel do professor tem sido cada vez mais investigado, já que ele deveria exercer sua autoridade em sala de aula.

Cremos que, se houve mudanças no que diz respeito à legitimidade das atitudes autoritárias, também houve modificações quanto ao papel social do professor e da escola. Cabe ponderar que, para muitos alunos, a exemplo dos que são referidos por Silva (2006, p. 90) em sua pesquisa, "a escola não representa um espaço privilegiado de aprendizagem", mas sim o lugar onde eles esperam os atendimentos e cuidados necessários às suas dificuldades, uma vez que não possuem a devida assistência na comunidade onde residem. E, como afirma a autora, "frustradas as expectativas dos alunos, pois também a escola não lhes supre as necessidades básicas, o resultado é desinteresse, indisciplina, agressividade, fracasso e consequente evasão escolar" (p. 90). Por essa ótica, a nosso ver, o professor deixa de ser o principal agente da educação, tornando-se um agente assistencial. A aprendizagem perde a importância, e outros benefícios sociais assumem a prioridade, deixando o ensino dos conteúdos em um plano secundário. Assim, podemos inferir que, desvalorizado em seu papel tradicional, que é o de ensinar o que aprendeu em seus estudos pregressos, o professor perde a autoridade, a qual 
advém principalmente de seus saberes e do seu preparo para atuar como um profissional do ensino. Quando isso não é valorizado, a autoridade docente também desvanece.

Morgado (2011, p. 114), ao comentar sobre os aspectos emocionais que entrelaçam a relação professor e aluno, também afirma que

\begin{abstract}
A autoridade do professor deriva de seu domínio dos conteúdos e de sua competência para ensinar e, portanto, é estritamente pedagógica. Ele exerce essa autoridade como mediador entre o aluno e os conteúdos culturais. Porém, caso a relação se estruture de modo a privilegiar o intercâmbio de afetos inconscientes em detrimento do ensino, a mediação será inadequada: outra autoridade, primordial e prototípica, tomará o lugar da autoridade pedagógica. A sobreposição da autoridade primordial à autoridade pedagógica resulta em sedução: mesmo sem perceber, o professor oculta o conhecimento em vez de mostrá-lo ao aluno.
\end{abstract}

A autora observa ainda que se torna difícil para o docente exercer adequadamente sua autoridade quando a sociedade em que vive a subtrai cada vez mais. E cita como exemplo o fato de o professor do ensino fundamental e médio ser muitas vezes visto pelos pais "mais como um inimigo de seus filhos do que como alguém responsável por ajudar a inseri-los no processo civilizatório" (MORGADO, 2011, p. 114). No entender da autora, trata-se de pais que "não querem mais envelhecer e que, ao mesmo tempo, delegam a educação de seus filhos quase que exclusivamente à escola" (p. 114).

Vemos então que, a par dos componentes psicológicos que podem interferir na autoridade docente, há também a pressão social que desvaloriza o papel do professor e sua importância na sociedade, ao mesmo tempo que cobra dele a responsabilidade pela educação da criança. De fato, decorrente das mudanças sociais, políticas e econômicas do mundo contemporâneo, observa-se a exigência de que a escola, agência educativa, participe também, juntamente com seus professores e equipe diretiva, de forma efetiva na formação educativa de crianças e jovens para a vivência em sociedade. No entanto, parece pertinente assinalar que, concretamente, isso não foi acompanhado por uma política de valorização social e econômica dos profissionais do magistério público. Essa desvalorização social do professor incide sobremaneira na sua autoridade em sala de aula.

Convém observar ainda que a relação de autoridade do professor sobre o aluno, que se expressa nas situações de ensino e aprendizagem, precisa ser reconhecida por este. Em outros termos, a autoridade do professor que se mostra por meio da sua competência profissional no trato com os conteúdos implica a aceitabilidade pelos alunos; pois, como sabemos, o professor na realização da docência precisa, conforme Tardif (2002), encaminhar os alunos à 
aprendizagem, e isso não ocorrerá "sem obter, de uma maneira ou de outra, seu consentimento, sua colaboração voluntária" (p. 221).

Nessa mesma direção, La Taille (1999, p. 22) também observa que

É ainda preciso que aqueles de quem se pede a obediência legitimem a hierarquia. Ora, se o professor for visto como 'empregado', a hierarquia se inverte. Mas se for visto como representante de algo que transcende a própria relação com seus alunos, como representante de valores aos quais todos devem aderir, a legitimidade necessária pode existir.

Considerado como um mero empregado, a autoridade do professor torna-se vulnerável. Porém, se for visto como representante de valores que transcendem a sua própria relação com os alunos, poderá legitimar a sua autoridade. E tais valores, a nosso ver, dizem respeito a valores éticos referentes ao respeito a si próprio e ao outro, à dignidade e à solidariedade para a melhoria da qualidade da vida humana.

Silva e Neves (2006, p. 10-11), valendo-se do entendimento de Crozier e Friedberg (1977) a respeito do caráter relacional do exercício do poder, o que "implica sempre a possibilidade de negociação e de adaptação dos actores envolvidos nessa relação", afirmam que também os alunos estão imbuídos de poder. Isso significa que, na relação entre os professores e os alunos, também estes dispõem de uma parcela de poder, embora ainda não legitimada pela instituição escolar ou pelos professores.

No exercício da autoridade docente, os alunos quase sempre destacam como valor o fato de o professor saber dialogar com eles, bem como saber liderar a classe sem valer-se de posturas autoritárias ou permissivas, as quais podem gerar atitudes negativas, tais como revolta, falta de controle, apatia, desinteresse etc. Uma forma de ampliar a compreensão das questões que envolvem a autoridade do professor poderia ser por meio do conhecimento do que verdadeiramente ocorre no contexto da vida na sala de aula.

Simon (2008, p. 7) investigou o conceito de indisciplina escolar, valendo-se de um conjunto de estudos acerca da autoridade e, dentre eles, destaca as concepções de Richard Sennett como importantes para compreender a noção de autoridade e, por seu intermédio, desenvolver o conceito de indisciplina escolar. Assim, para a autora, a autoridade

[...] pode ser entendida como uma expressão emocional do poder, um vínculo entre pessoas desiguais, que tem relação com a integridade e com a liderança; entretanto, não é determinada nem garantida pela posição hierárquica, nem pela competência, mas é definida no vínculo entre professores e alunos. (SIMON, 2008, p. 44). 
Entendendo que a indisciplina se relaciona com a autoridade, a autora destaca, entre os resultados alcançados no seu estudo, que "O conceito de indisciplina escolar pode ser entendido como um rompimento com o vínculo de autoridade docente em sala de aula" (p. 100).

Segundo Laterman (2002, p. 10), os alunos mencionam "a falta de autoridade na escola" como "a principal razão para a existência de um ambiente caótico, sem diálogo", pois os problemas, como dizem os alunos, são quase sempre "resolvidos com agressões verbais e físicas". Nesse contexto, são valorizados pelos alunos aqueles professores que "conseguem manter um clima mais adequado em suas aulas" (p. 9). Os alunos "sentem-se desrespeitados com o funcionamento instável do estabelecimento, sentem-se desprotegidos frente às ameaças dos colegas, não há respeito e admiração suficientes para fazer valer a imagem da autoridade" (LATERMAN, 2002, p. 13-14), o que provavelmente também pode provocar nos alunos condutas inadequadas.

Araújo (1996, p. 112) acredita que "É possível [o professor] ter um papel ativo, enérgico muitas vezes, sem ser autoritário, desde que os alunos sintam que são respeitados, que existe coerência em suas ações, que ele não busca privilégios para si ou para alguns alunos em detrimento de outros [...]".

Essas breves considerações acerca da autoridade do professor nos permitem inferir que, seja por qualquer um dos motivos apontados pelos autores acima, tais como a desvalorização social do professor, a quebra do vínculo entre este e o aluno, a falta de uma formação adequada, entre outros, o docente da escola contemporânea sente-se confuso quando se trata de garantir sua autoridade junto aos alunos, já que diversos componentes adversos frequentemente interferem em sua atuação na sala de aula. Sem autoridade, não há disciplina, e esta é uma questão que parece preocupar todos os que desejam uma escola mais qualificada para atender às exigências da clientela atual.

\section{O papel da família no controle da indisciplina}

A família da criança indisciplinada tem sido frequentemente julgada como ausente e alheia ao processo educacional dos filhos. Vimos que não se deve reduzir o fenômeno da indisciplina a uma única causa. Assim sendo, a atitude indiferente da família apresenta-se como mais um fator significativo da indisciplina. De fato, segundo Aquino (1996), de acordo com a perspectiva psicológica, a escola é fortemente abalada pelas alterações que ocorrem na família. O autor afirma que "a indisciplina apresenta-se como sintoma das relações descontínuas e conflitantes entre o espaço escolar e outras instituições sociais" (p. 48). E a família constitui a 
primeira instituição social responsável pela formação básica do sujeito (LA TAILLE, 2010). O papel da família, nesse sentido, está ligado ao conceito de "autoridade enquanto infra-estrutura psicológica para o trabalho pedagógico" (AQUINO, 1996, p. 48). Nessa direção, "[...] a indisciplina seria indício de uma carência estrutural que se alojaria na interioridade do aluno, determinada pelas transformações institucionais na família e desembocando nas relações escolares" (AQUINO, 1996, p. 48). Em outros termos, seria dizer que o aluno reproduz na escola os comportamentos que aprendeu (ou que deixou de aprender) em casa.

No entanto, o próprio autor adverte que, visto dessa forma, o problema da indisciplina seria atribuído exclusivamente ao aluno, o que não seria correto, assim como não o seria atribuir tal problema somente à escola ou às relações de cunho-pedagógico entre professor e aluno (AQUINO, 1996). A indisciplina transpassa todo o fazer pedagógico, sendo efeito das desordens sociais que historicamente atingem a escola e a família (AQUINO, 1996).

Justo (2010), ao tecer considerações sobre a escola como sendo o epicentro da crise social, afirma que "a escola está substituindo a família como instituição social primária encarregada do acolhimento e da formação básica do sujeito" (p. 37). Contemporaneamente, são inúmeras as demandas que recaem sobre ela. Cabe-lhe cuidar da formação biopsicológica, da futura profissão, sendo responsável por sanar os problemas sociais, como a violência, a desigualdade econômica, a gravidez na adolescência, abarcando todos os problemas que afligem o mundo atual. No entanto, a escola não está preparada para isso, nem recebe do poder público a ajuda de que necessita para fazer frente a tantas questões.

Por outro prisma, podemos assinalar que os responsáveis pela educação das crianças também estão vivendo, segundo Pedro-Silva (2010), uma crise de valores. "Por não saberem ou não refletirem sobre o quê e em quê acreditar, os pais sentem-se ignorantes quanto à maneira como devem educar sua prole" (p. 56). Devido à profusão de informações que recebem sobre conhecimentos psicológicos, pediátricos, pedagógicos, entre outros, "veem-se incapazes de ensinar aos seus filhos os primeiros passos de viver em sociedade" (p. 56). Essa crise, segundo o autor, também atingiu a escolarização formal. Os alunos não aprenderam a respeitar os limites necessários à convivência com os demais, e os educadores não sabem como vencer a indisciplina, a qual se tornou tema recorrente nas instituições escolares.

Nesse sentido, também La Taille (1996) aventa algumas explicações sobre a indisciplina na sala de aula aludindo à valorização do jovem em detrimento do mais velho: “A família, antes organizada em função dos adultos, passa a ser organizada em função das crianças. [...] Daí a atual queixa de falta de limites nas crianças. Os pais e professores têm medo de impô-los porque significaria impor o registro adulto, no qual não acreditam mais”. (LA TAILLE, 1996, p. 22). 
Segundo o autor, os pais tentam igualar-se às crianças, dizendo-se amigos, e não progenitores, pois têm medo de ensinar seus valores e, ao negar-lhes algo, causar-lhes o sentimento de frustração. "E o fato acaba por se repetir na escola". (LA TAILLE, 1996, p. 22). Tentando satisfazer o aluno, o professor prioriza aquilo que satisfaz o jovem e não o que deve ser aprendido: "A escola passa a ser o templo da juventude, não mais o templo do saber".

Também Rego (1996, p. 97) acredita que "a atitude dos pais e suas práticas de criação e educação são aspectos que interferem no desenvolvimento individual e, consequentemente, influenciam o comportamento da criança na escola".

Diante do que foi exposto, podemos concluir que se trata de uma crise decorrente dos valores contemporâneos que atinge pais e escola no que concerne a limites, à instrução, aos conteúdos e à autoridade. Por esse prisma, a indisciplina é um sintoma que exemplifica a falta de limites e a desvalorização do professor. Parece que importa sobretudo agradar ao aluno, ainda que seja em detrimento de sua formação, tal como o pai ao atender todos os desejos do filho com medo de frustrá-lo. Assim sendo, não basta o pai ou responsável ir à escola, muitas vezes para defender as atitudes inconvenientes do filho.

Muitas vezes, família e escola acusam-se mutuamente quando se trata do fracasso escolar, atribuindo uma à outra a culpa pela indisciplina que tanto desmotiva professores e alunos. Cremos que é importante refletir sobre essas questões a fim de manter aberto o diálogo entre pais, mestres e alunos. Dessa forma, talvez seja possível estabelecer compromissos que possam motivar todos os envolvidos no processo de aprendizagem.

\section{Procedimentos metodológicos}

Escolhemos como sujeitos de pesquisa 20 professores de língua portuguesa do ensino fundamental e médio ( 16 mulheres e 4 homens, entre 22 e 40 anos de idade), que frequentavam um curso de especialização lato sensu em uma cidade do interior paulista. Esses professores foram escolhidos por afirmarem que tinham problemas de indisciplina em sua prática docente. Nosso objetivo foi investigar as representações docentes acerca das causas da indisciplina na escola, bem como a que fatores eles atribuem o comportamento inadequado dos alunos. Entendemos o termo representação como sendo um sistema de classificação de categorias e nomes. Segundo Moscovici (2010), esse sistema inclui avaliar, caracterizar, categorizar, estereotipar, estigmatizar; enfim, trata-se de proceder a um julgamento de valor. Ao empregarmos, por exemplo, palavras adjetivantes para caracterizar e qualificar algo ou alguém, estamos realizando nosso julgamento de valor, ou seja, estamos estabelecendo uma relação 
positiva ou negativa ao que foi categorizado. 'E, neste ato, nós revelamos nossa 'teoria' da sociedade e da natureza humana" (MOSCOVICI, 2010, p. 62).

Para obtermos tais informações, solicitamos a nossos sujeitos de pesquisa que respondessem por escrito à seguinte questão: "Para melhorar a disciplina na escola, o que poderia ser feito?". Acreditamos que, ao responderem o que deveria ser mudado para melhorar a disciplina, certamente os docentes pesquisados estariam apontando quais eram as causas da indisciplina. Trata-se, portanto, de uma forma indireta de visualizar o que eles consideram como culpados pelos conflitos disciplinares na escola.

Para analisarmos as respostas de nossos sujeitos de pesquisa, empregamos a técnica da Análise de Conteúdo apresentada por Bardin (2010). Trata-se de um instrumento metodológico que se vale de um conjunto de técnicas específicas de análise que, ao proporcionar uma descrição analítica das mensagens tomadas como objeto de estudo, ajuda o pesquisador a identificar, interpretar e compreender as unidades de significação pertinentes ao conteúdo dos enunciados, bem como a efetivar inferências específicas ou interpretações causais mediante a depreensão de temas recorrentes ou pressupostos implícitos ou explícitos contidos nas respostas dos sujeitos da pesquisa. Assim, a inferência é o procedimento "que vem permitir a passagem, explícita e controlada", da descrição analítica do conteúdo das mensagens à interpretação (BARDIN, 2010, p. 41). Em outros termos, essa análise auxilia a reinterpretação das mensagens e o alcance de uma compreensão mais aprofundada de seus conteúdos mediante a inferência e a interpretação (MORAES, 1999).

Mais especificamente, as técnicas de Análise de Conteúdo explicitadas por Bardin (2010, p. 44) podem ser designadas, de modo geral, como "um conjunto de técnicas de análise das comunicações", sendo que em tais técnicas tem-se como propósito obter, por intermédio de procedimentos sistemáticos de descrição do conteúdo dos enunciados, "indicadores (quantitativos ou não) que permitam a inferência de conhecimentos relativos às condições de produção [...] destas mensagens".

Portanto, a intenção desse procedimento metodológico é a efetivação da análise do sentido latente, do não dito, que se encontra implícito no sentido manifesto expresso de qualquer mensagem. Nessa mesma direção, Bardin (2010, p. 45) afirma que "a análise de conteúdo procura conhecer aquilo que está por trás das palavras sobre as quais se debruça". Em outros termos, é preciso compreender o que está sendo estudado para alcançar os sentidos implícitos, ou, ainda, conforme a autora, "atingir através de significantes, ou de significados (manipulados), outros significados de natureza psicológica, sociológica, política, histórica, etc.” (BARDIN, 2010, p. 43). Nesse sentido, a análise de conteúdo relaciona as estruturas semânticas 
ou linguísticas com as estruturas psicológicas dos enunciados e busca perceber, por meio de processos inferenciais, as variáveis envolvidas no contexto em que um enunciado é produzido.

Procedemos a uma leitura atenta e cuidadosa do material de pesquisa, consoante as técnicas de análise de conteúdo de Bardin (2010), o que permitiu que alcançássemos a interpretação dos dados, bem como possibilitou a efetivação de inferências pelo cruzamento das respostas. Para isso, buscamos levantar nas respostas tanto os sentidos explícitos quanto os implícitos, o que nos propiciou condições para averiguar as diferenças de significação entre os conteúdos dos enunciados, bem como as nuanças de semelhança que eles apresentavam.

Dessa forma, foi possível estabelecer categorias que representassem os fatores a quem eles atribuem o comportamento inadequado dos alunos. A frequência (F) e o percentual (P) dizem respeito ao número de vezes que a categoria é mencionada nas respostas dadas por eles, e não ao número de participantes da pesquisa. Assim, um mesmo sujeito pode estar incluído em várias categorias. Abaixo, transcrevemos o quadro resultante das análises iniciais. Para melhorar a disciplina na escola, o que poderia ser feito?

Tabela 1 - Representações docentes sobre fatores que causam indisciplina

\begin{tabular}{|c|c|}
\hline $\begin{array}{l}\text { Categorias de } \\
\text { análise }\end{array}$ & $\frac{1}{\operatorname{los}}$ \\
\hline $\begin{array}{l}\text { Mudança } \\
\text { atitude } \\
\text { professor }\end{array}$ & $\begin{array}{l}\text { "Inicialmente o professor deve investigar as causas dessa indisciplina dos alunos ..." } \\
\text { "Poderia começar primeiro com o respeito dos professores para com os alunos." } \\
\text { "[...] acredito que a postura do professor, o domínio que tem sobre os conteúdos de sua } \\
\text { disciplina, a gestão de sala de aula e o ensino (exemplo) com relação ao que é um } \\
\text { comportamento adequado (respeito, participação) são fundamentais e, na minha opinião, é } \\
\text { exatamente isso o que falta a muitos professores." } \\
\text { "Mas o professor tem que complementar e ajudar o aluno na sua disciplina dentro da escola } \\
\text { e levando para outros lugares de sua convivência..." } \\
\text { "A falta de valorização do professor faz com que o mesmo vá desmotivado para a escola. } \\
\text { Dessa forma, o aluno não se interessa pelos estudos e a indisciplina toma conta das escolas." }\end{array}$ \\
\hline $\begin{array}{l}\text { Mudança } \\
\text { atitude } \\
\text { família } \\
\mathrm{F}-09 \\
\mathrm{P}-45 \%\end{array}$ & $\begin{array}{l}\text { "Apoio dos pais, pois muitos alunos são jogados nas escolas para que os pais se livrem dos } \\
\text { filhos." } \\
\text { "[...] deve ser trabalhado em casa primeiramente, é claro, com a família..." } \\
\text { "Poderia ser trabalhado desde a infância a questão de respeitar as regras e também é preciso } \\
\text { que os pais trabalhem juntamente com os professores, dando limites para seus filhos." } \\
\text { "Os pais também são fundamentais nessa função. Como sabemos, a educação vem de casa." } \\
\text { "A base disciplinar está na estrutura da família." }\end{array}$ \\
\hline $\begin{array}{l}\begin{array}{l}\text { Mudança na } \\
\text { atitude } \\
\text { equipe escolar }\end{array} \\
\mathrm{F}-04 \\
\mathrm{P}-20 \%\end{array}$ & $\begin{array}{l}\text { "Para melhorar a disciplina na escola, é necessário um trabalho em conjunto com toda equipe } \\
\text { escolar." } \\
\text { "[...] bem como a equipe gestora da escola deve se aproximar do aluno e ganhar dele a } \\
\text { confiança." } \\
\text { "A escola deve ter regras e segui-las. Por mais que a escola atual seja mais aberta aos alunos, } \\
\text { regras são importantes para impor limites aos estudantes." } \\
\text { "A escola precisa se tornar um local agradável tanto na aparência quanto nas experiências } \\
\text { lá vividas." }\end{array}$ \\
\hline $\begin{array}{l}\text { Valorização da } \\
\text { escola } \\
\mathrm{F}-03 \\
\mathrm{P}-15 \%\end{array}$ & $\begin{array}{l}\text { "[...] o aluno precisa ver sentido no ir pra escola, no estudar, isso precisa ser importante pra } \\
\text { ele, ele precisa entender como prioridade." } \\
\text { "Mostrar a importância de se estar em uma escola, para onde os conhecimentos adquiridos } \\
\text { podem levar." } \\
\text { "Conscientização dos alunos para a importância do estudo." }\end{array}$ \\
\hline
\end{tabular}




\section{Análises}

Uma vez que nosso objetivo era investigar como os sujeitos da pesquisa concebem as causas da indisciplina na escola e a que fatores eles atribuem o comportamento inadequado dos alunos, estabelecemos como categorias os fatores apontados por eles quanto à necessidade de mudança. Ora, o fato de eles desejarem mudar algo para vencer uma dificuldade significa que o problema reside nesse fator apontado. Assim, as categorias indicam a quem ou a quê os sujeitos da pesquisa (que são professores) atribuem as causas da indisciplina na escola.

As análises evidenciam que a maioria dos sujeitos considera que a atitude do professor deveria ser mudada, seja pelo fato de não investigar as causas da indisciplina, seja por não respeitar os alunos, seja por não ensiná-los a se comportarem adequadamente, entre outras. Parece que o professor julga-se o grande responsável pelas dificuldades que ora enfrenta, cabendo-lhe ser competente para resolver a indisciplina em sala de aula.

Vimos, no entanto, que o problema da indisciplina não pode ser interpretado de forma reducionista, apontando como culpado o professor (LA TAILLE, 1996). Ao contrário, pelo que foi dito pelos pesquisadores aqui citados em relação à crise atual, o professor é também vítima das vicissitudes sociais, da desvalorização crescente de sua profissão, sentindo-se desorientado diante dos reveses que o atingem na consecução de sua tarefa pedagógica (SILVA, 2006; MORGADO, 2011). Assim, teme ser autoritário, embora deseje garantir limites. Almeja manter sua autoridade em sala de aula sem ser impositivo e dominador. Precisa manter vínculos com os alunos, agradá-los, sem deixar de ser exigente. Enfim, parece que o professor arroga-se a incumbência de resolver os conflitos da escola, sentindo-se o grande responsável por existir indisciplina. Daí haver esse mal-estar geral quando se aborda esse assunto, até porque o professor, em sala de aula, é o mais atingido pelos confrontos com os alunos. A charge abaixo ilustra o quanto o professor é atualmente responsabilizado por qualquer fracasso escolar: 


\section{Figura 1}

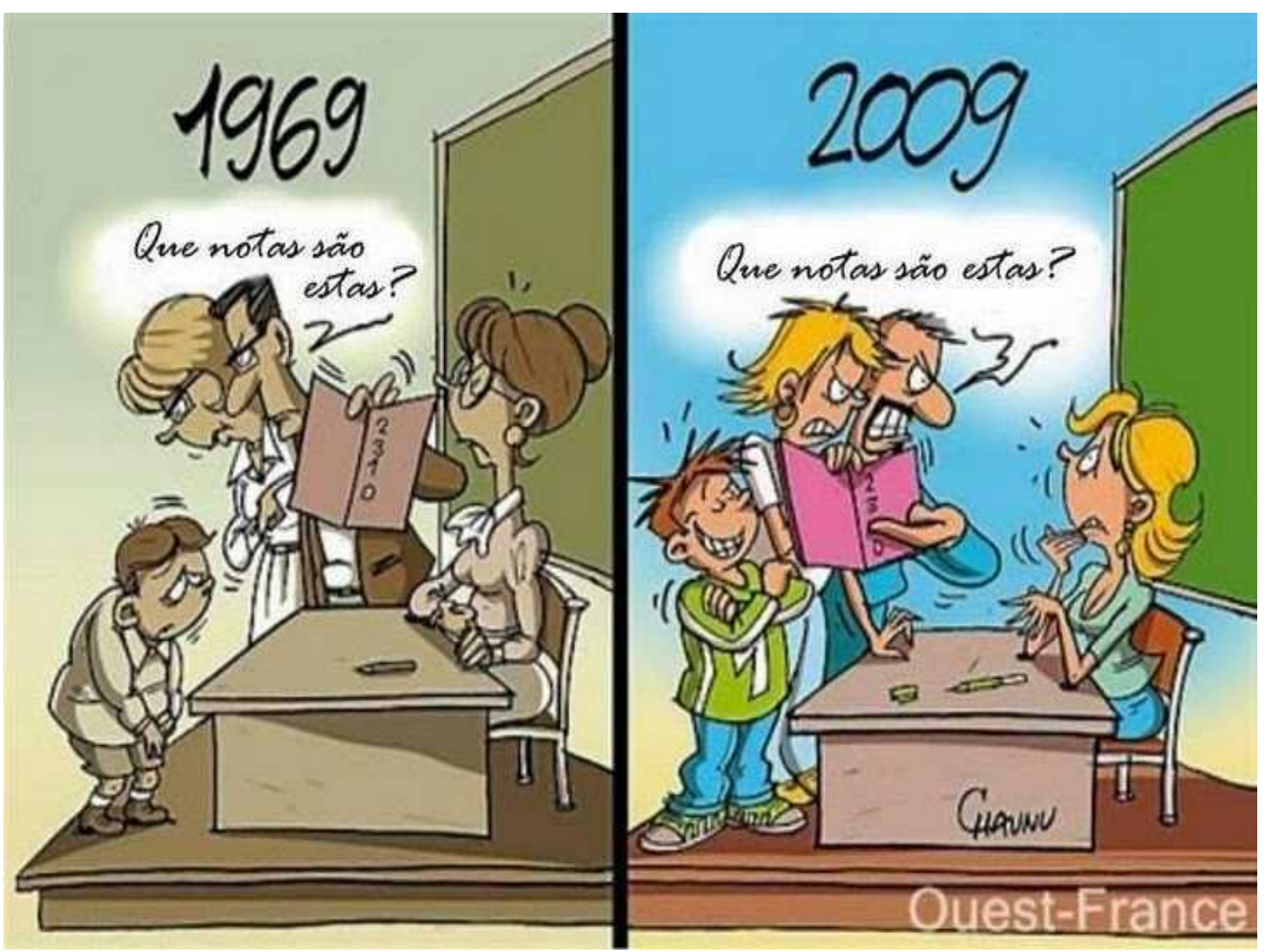

Fonte: www.humorcombobagem.com

Vemos que, no primeiro quadro, correspondente ao ano de 1969, é o aluno quem se sente envergonhado pelas notas insuficientes. No segundo quadro, referente a 2009, é apenas a professora quem deve envergonhar-se. A família e o aluno estão isentos de qualquer responsabilidade. Parece que os professores entrevistados nesta pesquisa sentem-se assim: submissos e fragilizados diante de problemas que não conseguem resolver, assumindo a meaculpa pela indisciplina de seus alunos.

O segundo motivo apontado pelos professores pesquisados diz respeito à família tanto em relação à educação pregressa à entrada do aluno na escola, quanto à participação efetiva da família no processo escolar do filho. Ao responsabilizar a família, o professor evidencia que percebe a crise de valores que se instalou no seio familiar devido à insegurança dos pais ou responsáveis, os quais se sentem desorientados em como conduzir seus filhos (JUSTO, 2010; AQUINO, 1996; PEDRO-SILVA, 2010).

Os sujeitos de pesquisa alegam que muitas vezes o aluno é entregue à escola para que essa o eduque, ou ainda sentem que "muitos alunos são jogados nas escolas para que os pais se 
livrem dos filhos". Acreditam que a obediência às regras deveria ser trabalhada na infância e que os pais deveriam dar continuidade a esse ensinamento apoiando os professores na escola. Sem poderem contar com a estrutura familiar, os professores pesquisados sentem-se desamparados na difícil tarefa de impor limites aos alunos. Aliás, como afirma La Taille (1996), essa é a queixa atual nas escolas: a falta de limites. E, segundo o autor, isso ocorre porque tanto os pais como os professores têm medo de desagradar os jovens ou de serem julgados como déspotas por eles.

Sem poder contar com a família e desvalorizado em seu papel, o professor tem alimentado a angústia de não conseguir controlar o comportamento de seus alunos. Isso sem falar em atos violentos que muitas vezes ocorrem nas escolas. Esse, aliás, seria um assunto que demandaria outro texto. De fato, embora não tenhamos abordado a questão da violência nas escolas (entendida aqui como atos de agressividade física ou moral), uma vez que não houve menção a ela por parte dos professores pesquisados, isso não significa que não seja um dado relevante e grave na escola atual. O fato é que o docente denuncia a ausência da família ao informar: "Como sabemos, a educação vem de casa." e, quando isso não acontece, a impressão é que os alunos “são jogados" na escola, na sala de aula, restando ao professor educá-los.

É interessante notar que apenas 4 entre os sujeitos pesquisados mencionam a importância da atuação da equipe gestora para minimizar os problemas de indisciplina. No entanto, sabe-se que o professor é uma das partes constituintes da escola, e sua atuação depende também do apoio que lhe é dado pela gestão escolar. Podemos dizer que a autoridade do professor esvanece quando não há aderência às regras por parte dos demais integrantes da escola. Daí a queixa de um dos professores pesquisados: "Por mais que a escola atual seja mais aberta aos alunos, regras são importantes para impor limites aos estudantes". Parece que, tal como adverte La Taille (1996), para satisfazer o aluno, a escola relativiza as regras, desautorizando muitas vezes o que foi estabelecido pelo professor.

Há ainda menção à valorização do estudo e, consequentemente, da escola para minimizar a indisciplina: “[...] o aluno precisa ver sentido no ir pra escola, no estudar, isso precisa ser importante pra ele, ele precisa entender como prioridade". Podemos inferir que essa desvalorização apontada pelo professor pesquisado estende-se também a sua própria função, já que ele é o agente educacional responsável pela transmissão dos conteúdos. Se a instrução que a escola oferece não é mais valorizada, tampouco o será o professor. Assim, a autoridade do docente, tão necessária à disciplina, fica comprometida devido a essa desvalorização do saber. De fato, como afirma La Taille (2010, p. 8), vivemos na era da valorização da informação imediata, e não do conhecimento; “Tampouco o conhecimento parece ser considerado hoje 102

Revista do GEL, São Paulo, v. 13, n. 1, p. 87-106, 2016 
como riqueza cuja posse, por si só, seria valorizada. Quantos alunos não perguntam: 'para quê me serve isso?"”.

De fato, a informação imediata, obtida muitas vezes pela Internet, em muito difere do conhecimento, uma vez que este pode ser definido "como um sistema de informações articuladas, articulação esta que lhe confere significado" (LA TAILLE, 2010, p. 6). Assim, não basta saber algo de forma desarticulada, é preciso que essa informação faça sentido ao relacionar-se com outras informações pertinentes ao assunto. Essa seria a função do professor: favorecer a articulação entre as informações a fim de que elas possam fazer sentido.

No entanto, poucos valorizam o conhecimento, a não ser quando esse acena com a possibilidade de ascensão social. Nesse caso, como afirma o autor, o conhecimento torna-se um meio de obter recursos financeiros, mas essa relação entre saber e recursos financeiros não ocorre necessariamente nos dias atuais. Há quem tenha bom salário sem ter se dedicado aos estudos, e "muitos até se vangloriam de sua ignorância" (LA TAILLE, 2010, p. 9). Assim, o professor não mais representa aquele que deve ser respeitado por deter o conhecimento; antes é considerado um mero empregado, em geral mal remunerado, cujo patrão é o aluno, seja devido aos impostos que os pais pagam, seja devido à mensalidade, quando se trata de ensino privado.

Em síntese, as mudanças sugeridas pelos professores pesquisados abrigam, em quase todas elas, a ideia de que a atitude do professor é a causa da indisciplina, o que incide na desvalorização do profissional que se dedica ao trabalho docente.

\section{Considerações finais}

A pesquisa realizada com 20 professores que se queixavam do fato de terem de enfrentar a indisciplina em sala de aula evidenciou que o docente atual atribui principalmente a si mesmo a responsabilidade ( a culpa) pelos problemas de indisciplina que prejudicam o seu trabalho. Embora saibamos que a compreensão do fenômeno da indisciplina requer que sejam visualizadas as múltiplas facetas que o compõem, parece que o professor não consegue desvencilhar-se do sentimento de desvalorização que contemporaneamente o acompanha. Tal sentimento é corroborado pela ausência da família na escola, uma vez que os pais, ao eximiremse da responsabilidade de estabelecer limites na educação das crianças, encarregam o professor de tal tarefa, culpando-o, caso este não obtenha sucesso. Porém, além da ausência dos pais, há também o sentimento de não poder contar com o apoio da equipe escolar. E, sem haver alicerces institucionais que garantam sua autoridade, o professor precisa equilibrar-se sozinho para ser 
querido e aceito pelos alunos; mas, ao mesmo tempo, garantir a obediência às regras nem sempre simpáticas ao alunado.

Pode-se inferir pela análise das respostas que, mesmo quando o professor deseja mudar a atitude dos pais ou da gestão escolar, ele se coloca como parte integrante dos fatores que causam a indisciplina, daí os termos trabalho conjunto; bem como, apoio dos pais, entre outros. Esses termos indicam sempre adição, o que significa que a figura do professor está no centro do problema, embora careça da adição de outros fatores, tais como os pais e dirigentes escolares, para vencer a indisciplina.

Diante de tais resultados, cremos que a discussão de qualquer problema referente à escola atual deve vir acompanhada pela tentativa de valorização do magistério e dos profissionais que a ele se consagram. E isso exige não só investimentos significativos, mas também uma política de resgate do real papel da educação para a qualidade da vida humana.

SILVA, Elisabeth Ramos da; ABUD, Maria José Milharezi.Teachers' representations about indiscipline facts in school: who is to blame? Revista do GEL, v. 13, n. 1, p. 87-106, 2016.

Abstract: This study presents a research conducted with 20 Portuguese language teachers from elementary and high schools, who complain about indiscipline in the school environment. The aim was to investigate their representations about the factors to which they attribute students' inadequate behavior. Therefore, it was requested to these teachers to answer the following question: To improve discipline in your school, what could be done? The factors mentioned by the teachers indicate to what or to whom they attribute the blame for students' inadequate behavior. The answers were analyzed under the constructs of Content Analysis as proposed by Bardin (2010). The results revealed that teachers blame their own performance as a major cause for recent indiscipline problems in school; in other words, in the representations of these teachers their own performance in the classroom is mainly blamed, which accentuates their devaluation and their loss of authority with students.

Keywords: Teachers' training. Indiscipline factors. Teachers' authority.

\section{Referências}

AMADO, J. S. Interacção pedagógica e indisciplina na aula. Porto: Edições ASA, 2001. Coleção: Perspectivas Actuais/Educação.

AQUINO, J. G. A desordem na relação professor-aluno: indisciplina, moralidade e conhecimento. In: AQUINO, J. G. (Org.). Indisciplina na escola: alternativas teóricas e práticas. 16. ed. São Paulo: Summus, 1996. p. 39-55. 
ARAÚJO, U. F. Moralidade e indisciplina: uma leitura possível a partir do referencial piagetiano. In: AQUINO, J. G. (Org.). Indisciplina na escola: alternativas teóricas e práticas. 16. ed. São Paulo: Summus, 1996. p. 103-115.

A educação e a construção da cidadania: eixos temáticos da ética e da democracia. In: ARAÚJO, U. F.; LODI, L. H. (Org.). Ética e cidadania: construindo valores na escola e na sociedade. Brasília, DF: Ministério da Educação, Secretaria de Educação Básica, 2007, v. 1, p. 11-21. Disponível em: <http://portal.mec.gov.br/ seb/arquivos/pdf/Etica/mliv_etic_cidad.pdf>. Acesso em: 07 mai. 2015.

BARDIN, L. Análise de conteúdo. 4. ed. Lisboa: Edições 70, 2010.

COSTA, E. P.; BARANDELA, T. Contribuindo para a melhoria socioeducativa da escola: Implementação de um plano de convivência. In: Seminário Internacional "Contributos da Psicologia em Contextos Educativos", 2, 2012, Braga. Atas... Braga: Universidade do Minho, 2012. p. 140-149. Disponível em: 〈http://webs.ie.uminho.pt/iisicpce/atas.pdf〉. Acesso em: 02 ago. 2014.

FERREIRA, A. B. H. Novo Dicionário Aurélio eletrônico versão 6.0. 4. ed. Curitiba: Positivo, 2009.

JUSTO, J. S. Escola no epicentro da crise social. In: LA TAILLE, Y.; PEDRO-SILVA, N.; JUSTO, J. S. Indisciplina/disciplina: ética, moral e ação do professor. 3. ed. Porto Alegre: Mediação, 2010. p. 23-53.

LA TAILLE, Y. A indisciplina e o sentimento de vergonha. In: AQUINO, J. G. (Org.). Indisciplina na escola: alternativas teóricas e práticas. 16. ed. São Paulo: Summus, 1996. p. 9-23.

Autoridade na escola. In: AQUINO, J. G. (Org.). Autoridade e autonomia na escola: alternativas teóricas e práticas. 4. ed. São Paulo: Summus, 1999. p. 9-30.

A escola e os valores: a ação do professor. In: LA TAILLE, Y.; PEDRO-SILVA, N.; JUSTO, J. S. Indisciplina/disciplina: ética, moral e ação do professor. 3. ed. Porto Alegre: Mediação, 2010. p. 5-21.

LATERMAN, I. Incivilidade e autoridade no meio escolar. In: Reunião Anual da Associação Nacional de Pós-Graduação em Educação, 25, 2002, Caxambu. Educação: manifestos, lutas e utopias. Anais... Caxambu: ANPEd / UFSC, 2002, p. 1-17. Disponível em: $<$ http://25reuniao.anped.org.br/tp251.htm\#gt14>. <25reuniao.anped.org.br/ ilanalatermant14.rtf>. Acesso em: 07 mai. 2015.

MORAES, R. Análise de conteúdo. Revista Educação, Porto Alegre, v. 22, n. 37, p. 7-32, 1999. Disponível em: <http://cliente.argo.com.br/ mgos/analise_de_conteudo_moraes.html>. Acesso em: 02 ago. 2014.

MORGADO, M. A. Autoridade e sedução na relação pedagógica. Psicologia da Educação, São Paulo, n. 32, p. 113-130, $1^{\circ}$ sem. de 2011. Disponível em:

<http://pepsic.bvsalud.org/pdf/psie/n32/n32a07.pdf>. Acesso em: 01 jun. 2015. 
MOSCOVICI, S. Representações sociais: investigações em psicologia social. 7. ed. Petrópolis: Vozes, 2010.

PEDRO-SILVA, N. Ética, indisciplina e relação professor-aluno. In: LA TAILLE, Y.; JUSTO, J. S.; PEDRO-SILVA, N. Indisciplina/disciplina: ética, moral e ação do professor. 3. ed. Porto Alegre: Mediação, 2010. p. 55-92.

REGO, T. C. R. A indisciplina e o processo educativo: uma análise na perspectiva vygotskiana. In: AQUINO, J. G. (Org.). Indisciplina na escola: alternativas teóricas e práticas. 16. ed. São Paulo: Summus, 1996. p. 83-101.

SILVA, M. E. P. Burnout: por que sofrem os professores? Estudos e Pesquisas em Psicologia, UERJ, Rio de Janeiro, v. 6, n. 1, p. 89-98, $1^{\circ}$ semestre de 2006. Disponível em: <http://www.revispsi.uerj.br/v6n1/artigos/PDF/v6n1a08.pdf>. Acesso em: 06 jun. 2015.

SILVA, M. P.; NEVES, I. P. Compreender a (in)disciplina na sala de aula: uma análise das relações de controlo e de poder. Revista Portuguesa de Educação, Universidade do Minho, Braga, v. 19, n. 1, p. 5-41, 2006. Disponível em:

<http://www.redalyc.org/articulo.oa?id=37419102>. <http://www.redalyc.org/pdf/374/ 37419102.pdf>. Acesso em: 10 set. 2014.

SIMON, I. Indisciplina escolar e autoridade docente. 2008.109 f. Dissertação (Mestrado em Educação) - Programa de Mestrado em Educação, Universidade Tuiuti do Paraná, Curitiba, 2008. Disponível em: <http://tede.utp.br/tde_busca/arquivo.php?cod Arquivo=209>. Acesso em: 10 mai. 2015.

TARDIF, M. Saberes docentes e formação profissional. Tradução de Francisco Pereira. Petrópolis: Vozes, 2002.

TREVISOL, M. T. C.; LOPES, A. L. V. A (in)disciplina na escola: sentidos atribuídos por profissionais da educação. In: Congresso Nacional de Educação - EDUCERE, 8, e Congresso Ibero-Americano sobre Violências nas Escolas - CIAVE, 3, PUCPR, 2008, Curitiba. Anais... Curitiba: Champagnat, 2008. p. 22-34. Disponível em: <http://www.pucpr.br/eventos/educere/educere2008/anais/pdf/909_555.pdf>. Acesso em: 10 mai. 2015.

Submetido em 29/06/2015

Aceito em 11/01/2016 